\title{
SISTEM INFORMASI PENYEWAAN BUS PARIWISATA BERBASIS WEB PADA PT ASLI PRIMA INTI KARYA
}

\author{
Wahyuddin $^{1)}$, Ahmad Kautsar ${ }^{2)}$, Renaldy Frans Sutisna ${ }^{3)}$ \\ ${ }^{1,2,3)}$ Fakultas Teknologi Informasi - Universitas Serang Raya \\ Jalan Raya Serang - Cilegon Km. 05 Taman Drangong \\ e-mail: wahyu.unsera@gmail.com ${ }^{1)}$, akautsar@gmail.com ${ }^{2}$, renaldyfranssutisna@gmail.com ${ }^{3}$ \\ * Korespondensi: e-mail: wahyu.unsera@gmail.com
}

\begin{abstract}
ABSTRAK
The existence of tourism facilities and infrastructure are elements to facilitate the process of tourism activities. With the facilities and infrastructure, it is hoped that tourism activities can run smoothly. Among the facilities in tourism activities are transportation/tour buses, travel operators, travel agents, restaurants, hotels/inns, tourist attractions, and tourist attractions. PT Asli Prima Inti Karya is a company engaged in tourism bus rental services, located in Pandeglang Regency, precisely in Labuan, Banten province. PT Asli Prima Inti Karya organizes several tour package and travel agency activities. The conventional bus rental system did not initially cause problems in terms of service. Along with the increasing demand for rental, it takes a complete service so that customers can be served well. The author analyzes the problem and makes a bus rental application design as a solution to the problems in serving customers who will rent buses. The application design uses UML, and uses the Sublime Text 3 programming language, PHP, XAMPP Version 3.2.4, and the database used is MySQL. The results of the application test show that the existence of this information system can make it easier for tenants to carry out the bus rental process.
\end{abstract}

Keywords: System, Information, Bus Rental, Web Based.

\begin{abstract}
Keberadaan Sarana dan prasarana pariwisata merupakan unsur-unsur untuk memudahkan terjadinya proses kegiatan pariwisata. Dengan adanya sarana dan prasarana diharapkan kegiatan pariwisata dapat berjalan dengan lancar. Diantara sarana dalam kegiatan pariwisata adalah angkutan/bus wisata, operator perjalanan, agen perjalanan, rumah makan, hotel/penginapan, objek wisata, dan atraksi wisata. PT Asli Prima Inti Karya merupakan perusahaan yang bergerak dalam bidang jasa penyewaan bus pariwisata, berlokasi di Kabupaten Pandeglang tepatnya di Labuan propinsi Banten. PT Asli Prima Inti Karya menyelenggarakan beberapa kegiatan paket wisata dan agen perjalanan. Sistem penyewaan bus secara konvensional pada awalnya tidak menimbulkan permasalahan dalam hal pelayanan. Seiring dengan bertambahnya permintaan sewa, dibutuhkan pelayanan yang paripurna agar pelanggan dapat terlayani dengan baik. Penulis melakukan analisa permasalahan dan membuat perancangan aplikasi peyewaan bus sebagai solusi dari permasalahan yang dalam melayani para pelanggan yang akan menyewa bus. Perancangan aplikasi menggunakan UML, dan menggunakan bahasa pemrograman Sublime Text 3, PHP, XAMPP Versi 3.2.4, serta database yang digunakan adalah MySQL. Hasil pengujian aplikasi menunjukkan bahwa dengan adanya sistem informasi ini dapat memudahkan penyewa dalam melakukan proses penyewaan bus.
\end{abstract}

Kata kunci : Sistem, Informasi, Penyewaan Bus, Berbasis Web.

\section{Pendahuluan}

Dalam kaitannya dengan kehidupan manusia, transportasi memiliki peranan signifikan dalam aspek sosial, ekonomi, dan lingkungan. Dalam aspek perekonomian, transportasi mempunyai pengaruh yang besar dan pentingnya transportasi tentunya diimbangi dengan keterlibatan atau partisipasi aktif dari pihakpihak yang terkait di dalamnya yaitu konsumen. PT Asli Prima Inti Karya merupakan salah satu perusahaan yang bergerak dalam bidang jasa penyewaan bus pariwisata. Sistem penyewaan bus yang diterapkan oleh 
perusahaan tersebut masih bersifat konvensional, konsumen yang akan melakukan penyewaan bus datang secara langsung ke lokasi tempat penyewaan bus tersebut. Penyewa kemudian menemui karyawan untuk melakukan pemesanan bus, lalu karyawan melakukan pengecekan ketersediaan bus yang akan disewa. Setelah bus yang aka disewa tersedia, konsumen melakukan proses pembayaran. Hal ini tentunya akan menjadi kendala bagi konsumen yang mempunyai keterbatasan waktu. Kehadiran sistem informasi dapat membuat kemudahan-kemudahan, diantaranya dalam hal mempermudah koordinasi. Para pelanggan/penyewa bus seyogyanya tidak harus datang ke lokasi penyewaan karena dapat dilakukan tanpa datang ke tempat penyewaan bus tersebut. Biaya operasionalpun dapat ditekan dengan adanya sistem informasi tersebut. Dengan demikian, adanya sistem informasi tersebut akan dapat menguntungkan kedua belah pihak, baik bagi perusahaan maupun bagi pelanggan/penyewa bus. Perusahaan dapat memberikan kemudahan bagi penyewa bus dan dengan layanan yang paripurna pelanggan dapat terlayani dengan baik sehingga memungkinkan terjadinya peyewaan bus pada waktu yang berikutnya. Sementara penyewa bus akan merasa dimudahkan karena tidak perlu datang ke lokasi penyewaan bus, sehngga dapat menekan biaya operasional dan juga dapat menghemat waktu.

\section{PENELITIAN TERKAIT}

\subsection{Penelitian Terkait}

Sistem Informasi Pelayanan Jasa Tour Dan Travel Berbasis Web (Studi Kasus Smart Tour), merupakan penelitian yang dilakukan oleh Riskiono, S. D. \& Reginal U. Penelitian ini dipublikasikan di Jurnal Informasi dan Komputer Volume 6 Nomor 2 Tahun 2018. Penelitian ini dilakukan karena kurang lengkapnya data dan informasi yang ada di penyelenggara tour dan travel sehingga pelayanan kepada pelanggan tidak dapat terlayani dengan baik. Permalasahan yang lain adalah karena data yang dikelola masih bersifat konvensional. Hasil dari penelitian ini adalah sebuah sistem informasi tentang paket liburan pariwisata dan traveel penyewaan mobil. Aplikasi ini dapat menampilkan data dan informasi yang sangat membantu para pelanggan. Sistem ini juga dapat menangani pengelolaan data yang dilakukan oleh admin, sehingga memudahkan para pengguna data.

Pada penelitian yang dilakukan oleh Renny Oktapiani, Dicki Prayudi, Resti Yulistria, Nur Islamiyati, Siti Nazmah dengan judul Aplikasi Penyewaan Bus Berbasis Web Pada PO. Nuansa Ilham Sukabumi, terdapat permasalahan tentang data-data transaksi yang pendataannya masih dilakukan secara manual. Sementara untuk melakukan pemesanan, pelanggan harus datang ke lokasi penyewaan bus tersebut. Hasil dari penelitian ini berupa aplikasi yang dapat membantu dalam hal pendataan dan transaksi, sehingga datadatanya menjadi terorganisir dan lebih baik. Hasil penelitian ini telah dipublikasikan pada jurnal swabumi volume 7 nomor 2 tahun 2019.

\subsection{Metode Pengembangan}

Dalam perancangan sistem informasi ini, metode pengembangan sistem yang digunakan adalah metode waterfall, model klasik yang bersifat sistematis, dan berurutan.Tahapan yang dilakukan meliputi tahapan :

a) System Engineering, merupakan tahap untuk melakukan pengumpulan data dan penetapan kebutuhan semua elemen sistem.

b) Requirement Analysis, merupakan tahap untuk menganalisis hal-hal yang diperlukan dalam pelaksanaan proyek pembuatan atau pengembangan perangkat lunak.

c) Design, merupakan tahap penerjemahan dari keperluan atau data yang telah dianalisis ke dalam bentuk yang mudah dimengerti oleh pemakai (user).

d) Coding, merupakan tahap untuk menerjemahkan data atau pemecahan masalah yang telah dirancang ke dalam bahasa pemrograman komputer yang telah ditentukan

e) Testing, merupakan tahap untuk melakukan uji coba terhadap program yang telah dibuat.

f) Maintenance, merupakan tahap perawatan perangkat lunak yang telah selesai dengan keinginan user dan terhindar dari gangguan-gangguan yang menyebabkan kerusakan. 


\subsection{Kebutuhan Software}

\subsubsection{Sublime}

Menurut Sumarna (2019:51), Sublime adalah aplikasi editor untuk kode dan teks yang dapat berjalan di berbagai platform operating system dengan menggunakan teknologi Phyton APL. Terciptanya aplikasi ini terinspirasi dari aplikasi Vim, aplikasi ini sangatlah fleksibel dan powerfull. Fungsionalitas dari aplikasi ini dapat dikembangkan dengan menggunakan sublime-packages.

\subsubsection{Xampp}

Menurut Wardana (2010:8) dalam Maulana (2017:9) XAMPP adalah paket software yang didalamnya sudah terkandung Web Server Apache, database MySql dan PHP Interpreter, Software ini gratis dan dapat di download untuk versi windows.

Menurut Isnandi (2014:40), XAMPP merupakan singkatan dari X (empat sistem operasi apapun), Apache, MySql, PHP, Perl. XAMPP merupakan tool yang menyediakan paket perangkat lunak ke dalam satu buah paket. Dalam paketnya sudah terdapat Apache (Web Server), MySQL (database), PHP (server side scripting), Perl, FTP server, phpMyAdmin dan berbagai pustaka bantu lainnya. Dengan menginstal XAMPP maka tidak perlu lagi melakukan instalasi dan konfigurasi web server Apache, PHP dan MySQL secara manual. XAMPP akan menginstalasi dan mengkonfigurasikannya secara otomatis.

\subsubsection{World Wide Web}

Menurut Sunarto, (2009:52) dalam Wibowo (2014:38), World Wide Web adalah fasilitas internet yang menghubungkan dokumen dalam lingkup lokal maupun jarak jauh. Dokumen web disebut web page dan link dalam web membuat user bisa pindah dari satu page ke page lain (hyper text), baik antar page yang disimpan dalam server yang sama atau server di seluruh dunia. Pages diakses dan dibaca melalui web browser seperti netscape navigator atau internet explorer.

World Wide Web sering disingkat sebagai WWW atau web saja, yaitu sebuah sistem dimana informasi dapat dinikmati dalam bentuk teks, gambar, suara, dan lain-lain serta dapat diakses oleh perangkat lunak yang disebut browser. Informasi di web pada umumnya ditulis dalam format HTML. Informasi lainnya disajikan dalam bentuk grafis (dalam format GIF, JPG, PNG), suara (dalam format AU, WAV), dan objek multimedia lainnya (seperti MIDI, Shockwave, Quicktime Movie, 3D World), WWW dijalankan dalam server yang disebut HTTPD.

\section{METODOLOGI PENELITIAN}

\subsection{Tipe Penelitian}

Penelitian ini merupakan penelitian terapan dengan tujuan untuk memecahkan masalah praktis yang terdapat di lokasi penelitian.Penelitian terapan adalah salah satu jenis penelitian yang bertujuan untuk memberikan solusi atas permasalahan tertentu secara praktis. Penelitian ini tidak berfokus pada pengembangan sebuah ide, teori, atau gagasan, tetapi lebih berfokus pada penerapan hasil penelitian untuk dapat diterapkan dalam kehidupan sehari-hari. Penelitian terapan ini juga dilakukan untuk mencari solusi tentang masalah-masalah tertentu yang ada di lapangan.

\subsection{Pengumpulan Data}

Teknik pengumpulan data merupakan salah satu hal yang krusial dan penting agar penelitian yang dilakukan lebih lancar dan terkendali. Menentukan teknik pengumpulan data sangat penting dilakukan untuk meminimalisir hambatan dan kesalahan dalam melakukan penelitian. Dalam hal ini, peneliti langsung terjun ke lokasi penelitian.

Setelah melakukan identifikasi dan perumusan masalah pada PT. Asli Prima Inti Karya. Langkah selanjutnya yang dilakukan adalah mencari informasi pada media informasi atau internet, buku-buku, jurnal, maupun sumber-sumber informasi lainnya untuk mengembangkan sistem informasi penyewaan bus pariwisata online menjadi sebuah program aplikasi berbasis web. Pengumpulan data dilakukan melalaui kegiatan : 
a) Wawancara

Kegiatan wawancara dilakukan secara langsung dengan pihak terkait di PT. Asli Prima Inti Karya. Pertanyaan dilakukan yang berkaitan dengan kebijakan ditujukan langsung pada pimpinan, sementara pertanyaan yang bersifat operasional ditujukan pada bagian-bagian yang terkait dengan pelayanan. Dibutuhkan ketelitian dalam mendapatkan data-data yang valid.

b) Observasi

Observasi dilakukan dengan cara melakukan pengamatan secara langsung pada objek penelitian. Dengan melakukan observasi peneliti dapat melihat langsung keadaan yang sesungguhnya, baik kelebihan maupun kekurangannya.

c) Dokumentasi

Dengan teknik dokumentasi ini, peneliti dapat memperoleh informasi bukan dari orang sebagai narasumber, tetapi mereka memperoleh informasi dari macam-macam sumber tertulis seperti buku-buku, dokumen, dan sebagainya. Studi dokumentasi dalam penelitian merupakan pelengkap dari pengguna metode observasi dan wawancara, studi dokumentasi yaitu mengumpulkan dokumen dan data-data yang diperlukan dalam permasalahan penelitian lalu ditelaah secara intens sehingga dapat mendukung dan menambah kepercayaan dan pembuktian suatu kejadian.

\section{HASIL DAN PEMBAHASAN}

\subsection{Use Case Diagaram}

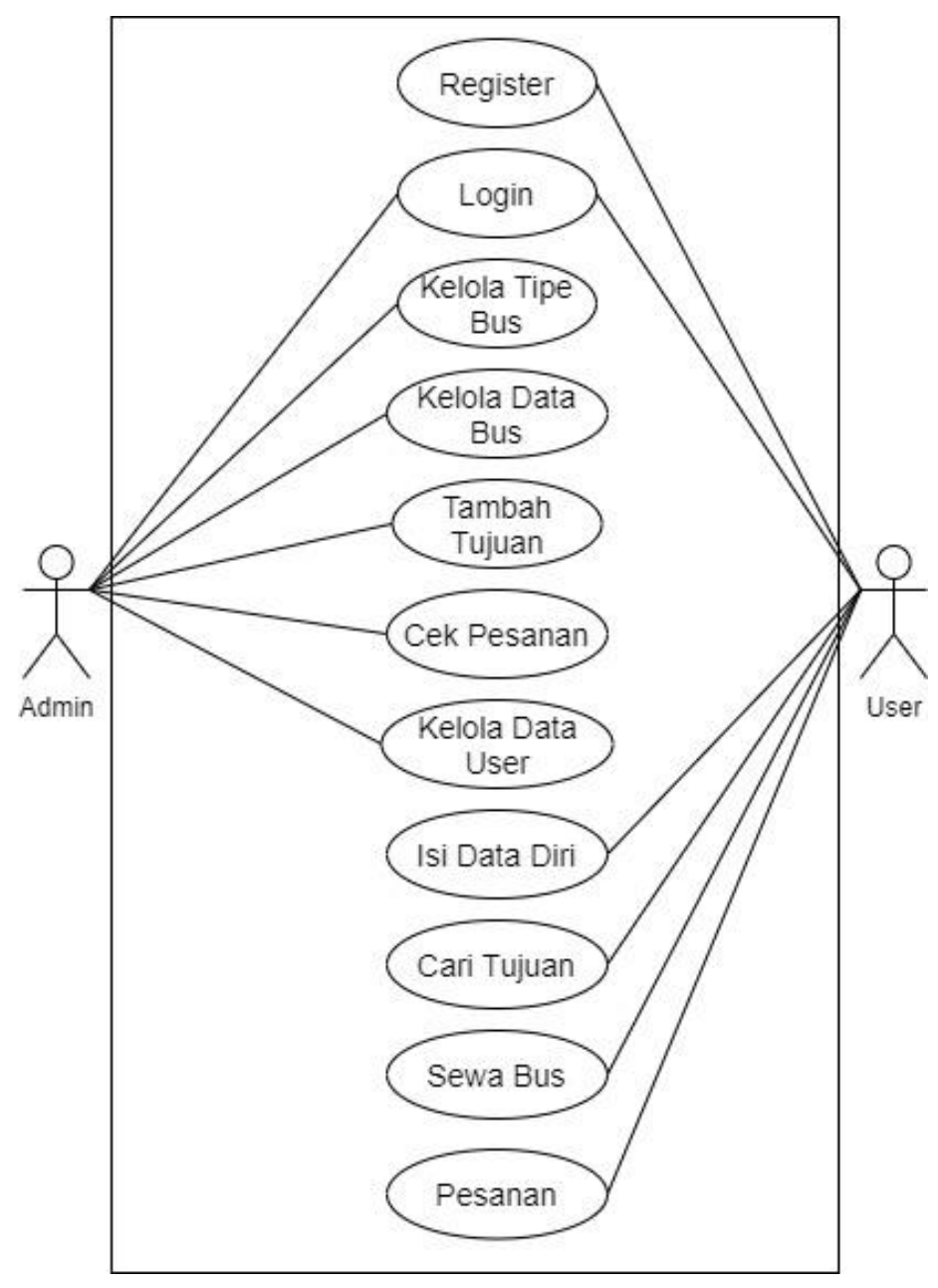

Gambar 1. Use Case Diagram 
Dalam use diagram diatas, terdapat dua actor yang terlibat dalam sistem ini. Setelah masuk aplikasi dengan memilih Login, Admin dapat mengelola tipe bus, data bus, tujuan wisata, pengecekan pesanan dan mengelola data user. Sementara User, setelah Login dapat melakukan pemesanan setelah mengisi Data Diri, Tujuan Wisata, Sewa Bus.

\subsection{Activity Diagaram}
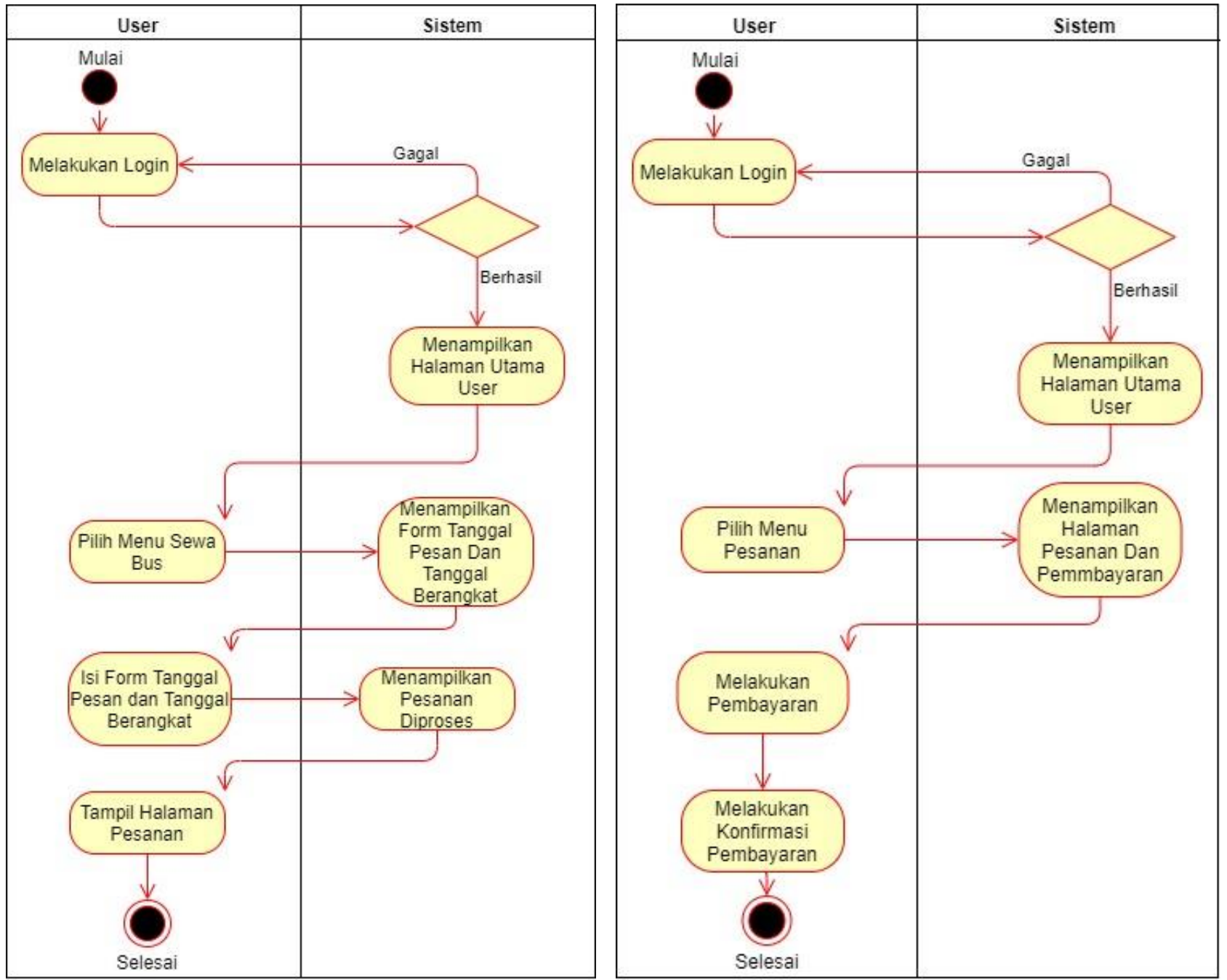

Gambar 2. Acitivity Diagram Penyewaan dan Pembayaran

Pada activity diagram ini terlihat model proses yang terjadi pada sistem informasi penyewaan bus pariwisata. Aktivitas user/penyewa tergambarkan pada diagram tersebut, berikut tahapan-tahapan yang dilaluinya dalam sistem tersebut. Ketika user telah berhasil login, maka user akan ditampilkan pada halaman utama. Setelah berada pada halaman utama, maka akan tersedia pilihan untuk melakukan penyewaan bus, tanggal pesan dan tanggal berangkat, dan selanjutnya akan diproses.

Aktifitas dalam melakukan pembayaran, dapat dimulai dari masuk aplikasi melalui login, setelah tampil halaman utama, dilanjutkan dengan memilih menu pesanan sampai ditampilkan halaman pesanan dan pembayaran. Apabila telah melakukan transfer, maka bukti transfer tersebut tinggal diupload dan melakukan konfirmasi tentang pembayaran tersebut. 


\subsection{Class Diagaram}

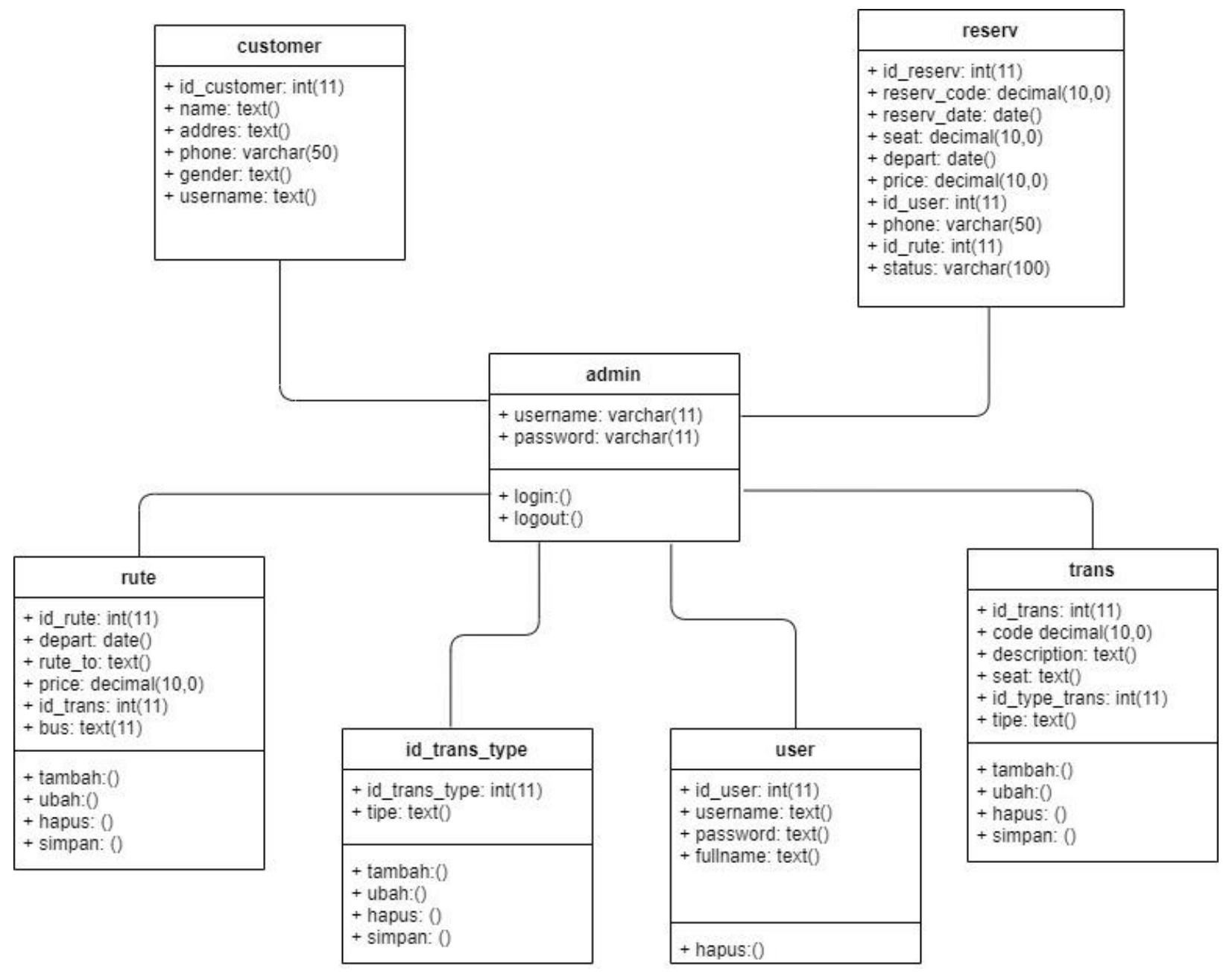

Gambar 3. Class Case Diagram

\subsection{Implementasi}

Penerapan aplikasi dari hasil perancangan sistem yang telah dibuat dilakukan untuk mengetahui hasil rancangan yang telah dibuat. Aplikasi dibuat menggunakan bahasa pemograman PHP, XAMPP versi 3.2.4, Sublime Text 3, UML, dan MySql sebagai media penyimpanan data (database).

Dalam implementasi sistem informasi penyewaan bus pariwisata Pada PT Asli Prima Inti Karya Berbasis Web harus didukung oleh perangkat lunak agar sistem berjalan maksimal. Perangkat lunak yang dibutuhkan terdiri dari Sistem Operasi Windows dan Web Browser, yaitu browser internet sederhana yang dirancang untuk menampilkan halaman PHP, HTML, Javascript, dan lain-lain dengan benar, misalnya : Google Chrome, Mozila Firefox, Internet Explorer dan lain-lain. Selain sitem operasi dan web browser, dibutuhkan lokal server untuk dijadikan sebagai localhost, dapat dilakukan dengan melakukan install software XAMPP. 
JURSISTEKNI (Jurnal Sistem Informasi dan Teknologi Informasi) Vol 4, No.1, January 2022: Hal 18 - 27 ISSN.

\section{$P: 2715-1875, E: 2715-1883$}

\subsection{Antar Muka Aplikasi}
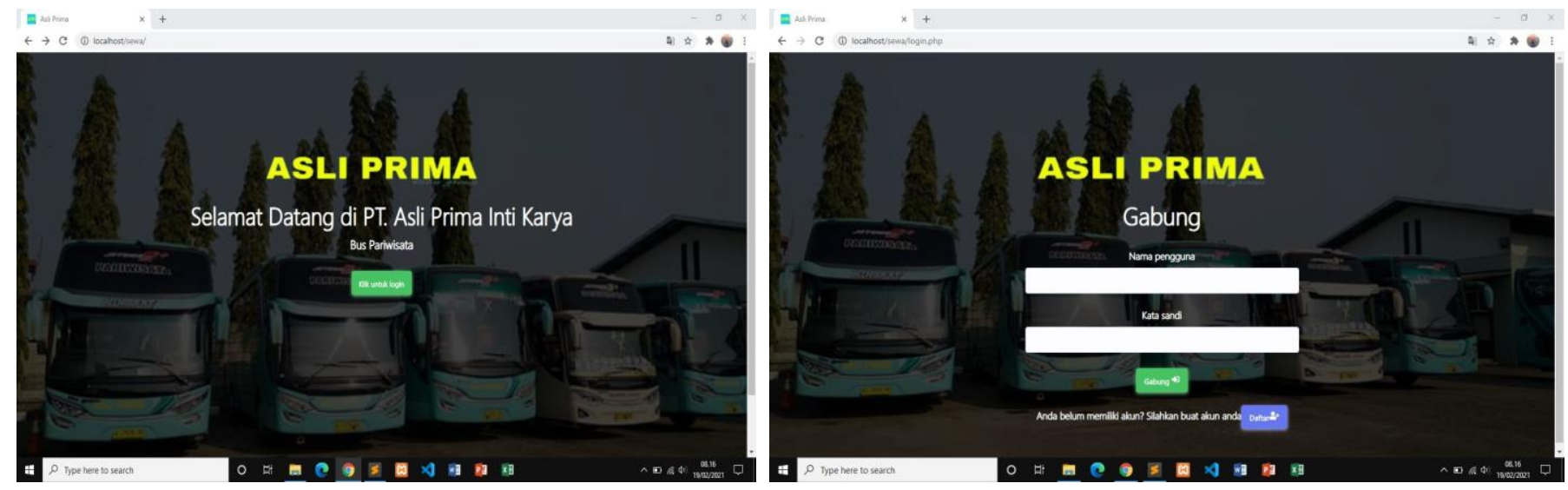

Gambar 4. Halaman Awal dan Login Pengguna

Ketika aplikasi dijalankan, makan akan terbuka tampilan awal dan ketika dipilih Login maka akan tampil halaman login untuk pengguna. Para pengguna yang akan menyewa bus diharuskan masuk ke aplikasi dan mengisi data-data yang diperlukan untuk melakukan penyewaan bus pariwisata.
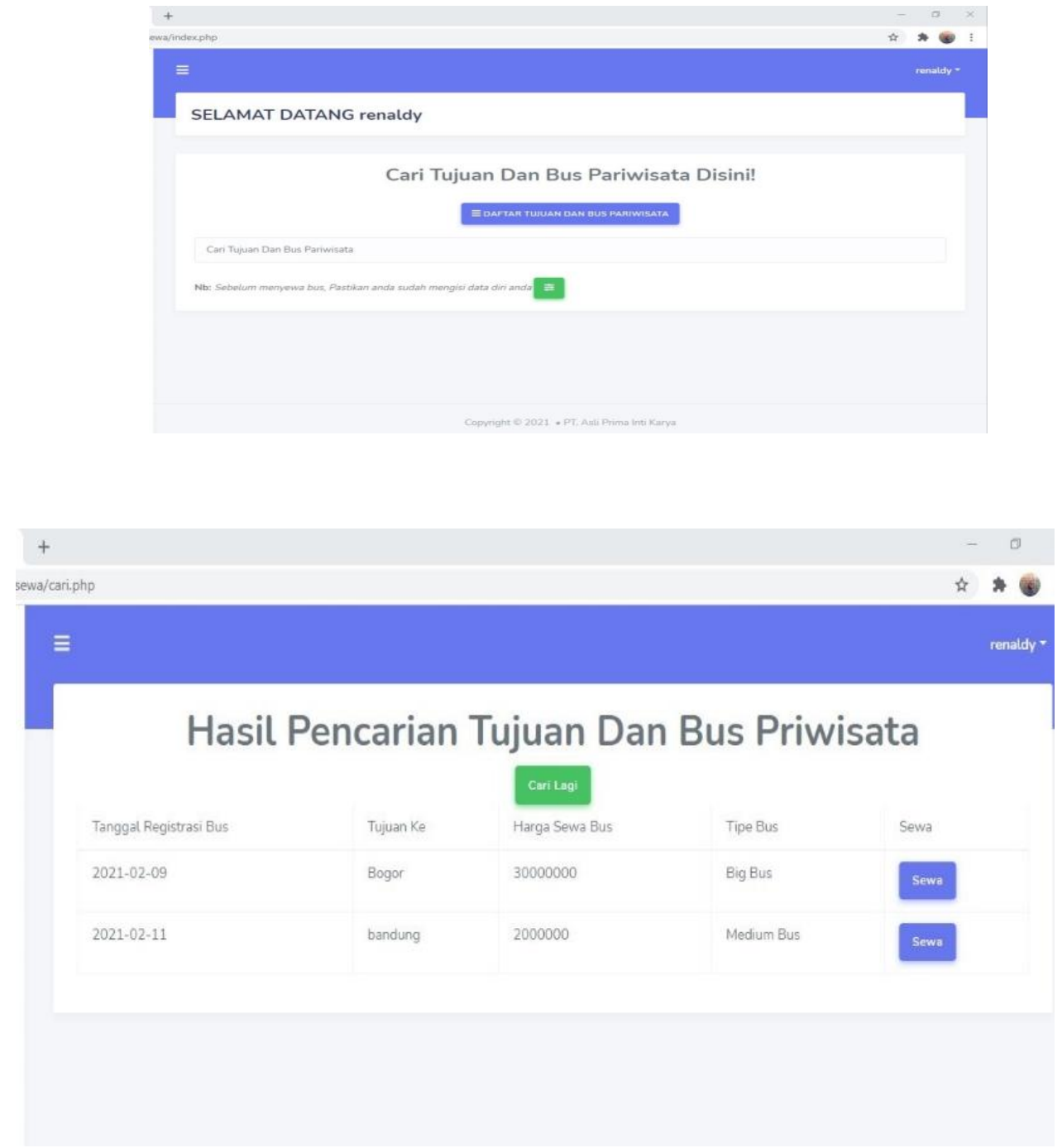

Gambar 5. Halaman untuk melihat Tujuan 
Pada halaman ini pengguna dapat melihat tujuan yang dapat dilayani oleh bus pariwisata. Pengguna dapat melihat apakah tujuan yang ingin dituju dalam penyewaan bus ini tersedia atau tidak. Setelah mencari dan memilih tujuan, selanjutnya dapat memilih menu halaman sewa bus. Pada menu halaman sewa bus, penyewa bus dapat melengkapi data-data yang dibutuhkan untuk melakukan penyewaan bus tersebut. Datadata yang masukkan harus jelas dan sesuai dengan ketentuan agar proses dapat berjalan dengan baik. Tampilan bentuk form untuk mengisi data-data tersebut seperti gambar 6 berikut ini :

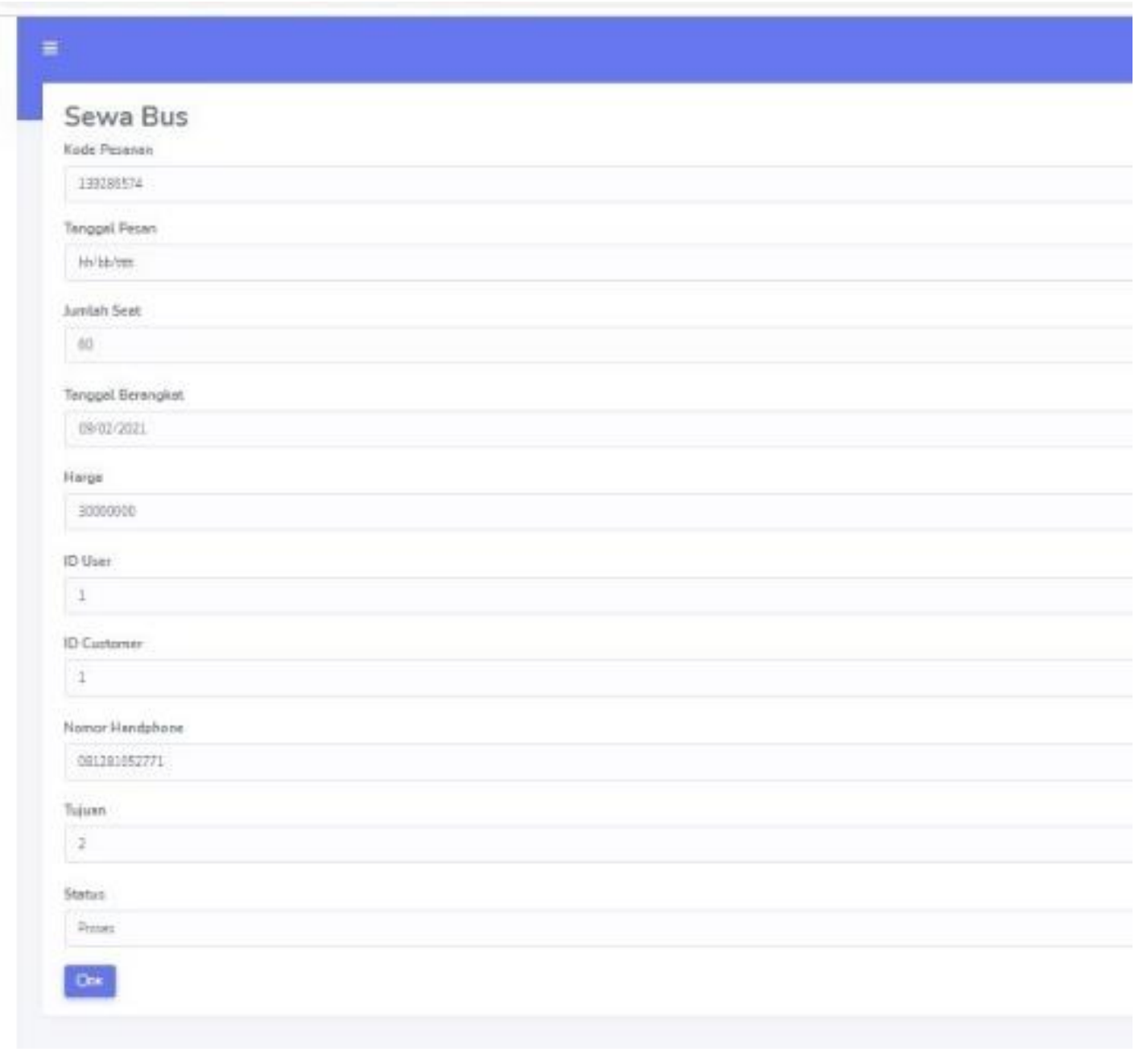

\section{Gambar 6. Halaman Sewa Bus}

Setelah melengkapi data-data pada form sewa bus, selanjutnya penyewa diarahkan pada form pembayaran. Setelah penyewa melakukan pembayaran, baik melalui transfer ATM ataupun media transfer yang lainnya, penyewa bus dapat melakukan upload bukti transfer pembayaran tersebut melalui halaman upload bukti pembayaran. 


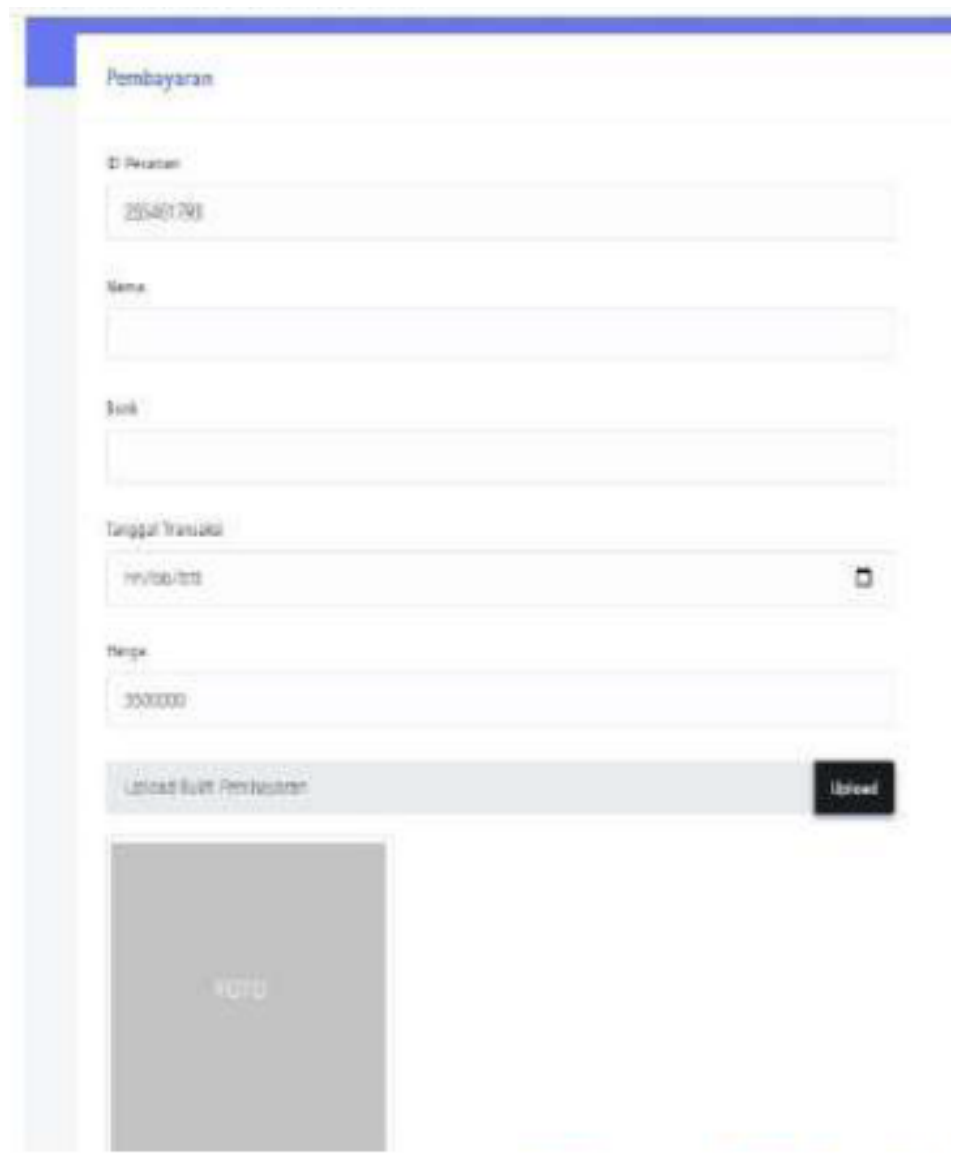

Gambar 7. Halaman upload bukti pembayaran

\section{KESIMPULAN}

Berdasarkan penelitian yang telah dilakukan, maka dapat diambil kesimpulan sebagai berikut :

1. Aplikasi penyewaan bus pariwisata berbasis web dapat dibuat dengan menggunakan bahasa pemrograman Sublime Text 3, PHP, UML, XAMPP Versi 3.2.4, dan database yang dipakai yaitu MySQL.

2. Dalam implementasi sistem informasi penyewaan bus pariwisata di PT Asli Prima Inti Karya sudah menghasilkan halaman web yang terdiri dari menu admin dan menu user. Pada menu admin didalamnya terdapat halaman login, halaman kelola tipe bus, halaman kelola data bus, halaman tambah tujuan, halaman cek pesanan, dan halaman kelola data user. Sedangkan pada menu user terdapat halaman utama register, halaman login, halaman isi data diri, halaman cari tujuan, halaman sewa bus, halaman pesanan dan halaman transaksi.

3. Dengan adanya aplikasi sistem penyewaan bus ini, sangat membantu pihak perusahaan penyewaan bus dan juga bagi para penyewa bus tersebut. Pihak perusahaan dapat membuat dan mengelola datadata para penyewa bus dengan waktu yang singkat. Sementara para penyewa sangat dimudahkan dalam proses penyewaan bus ini, tidak perlu datang ke lokasi penyewaan bus sehingga dapat menghemat biaya dan waktu. 


\section{DAFTAR PUSTAKa}

[1] Hekmatiar, A., \& Erlangga, F. "Perancangan Sistem Informasi Penyewaan Bus Pariwisata Berbasis Java". In Semnas Ristek, Volume 4, Nomor 1, January 2020.

[2] Kurniawan, A., Abadi, L. P., \& Wilson, A. "Perancangan Sistem Informasi Penyewaan Bus Pariwisata di Rizky Jaya Transport Berbasis Java”. Jurnal Riset dan Aplikasi Mahasiswa Informatika (JRAMI), Volume 1 Nomor 1, tahun 2020.

[3] Maya, S. "Strategi Peningkatan Penjualan Usaha Kecil Menegah Melalui E-Commerce Studi Kasus: Mitra Ukm Perusahaan X. JABE", Journal of Applied Business and Economic, volume 2 nomor 3, hal:271-279. Tahun 2016.

[4] Nisa, Y. "Sistem Informasi Penyewaan Bus Online Berbasis Web Pada Dinas Perhubungan Kabupaten Barito Kuala". PHASTI, volume 3 nomor 02, hal: 19-24, tahun 2017

[5] Prihandoyo, M. T. "Unified Modeling Language (UML) Model Untuk Pengembangan Sistem Informasi Akademik Berbasis Web". Jurnal Informatika: Jurnal Pengembangan IT, volume 3 nomor 1, 126-129. Tahun 2018

[6] Putra, T. A., Mursityo, Y. T., \& Pramono, D. "Pengembangan Sistem Informasi Penggajian Karyawan Bus Pariwisata PT. Mahkota Mitra Sentosa Menggunakan Metode Rational Unified Process (RUP)". Jurnal Pengembangan Teknologi Informasi dan Ilmu Komputer e-ISSN, 2548, 964X. tahun 2018

[7] Ramdhani, A. I., Khasanah, S., \& Farizki, R. "Sistem Aplikasi Pemesanan Tiket Bus Berbasis Website Pada PO Sinar Jaya". Syntax, volume 2 nomor 9, halaman 515. Tahun 2020.

[8] Riskiono, S. D., \& Reginal, U. "Sistem Informasi Pelayanan Jasa Tour Dan Travel Berbasis Web (Studi Kasus Smart Tour)". Jurnal Informasi dan Komputer, volume 6 nomor 2, hal: 51-62. Tahun 2018.

[9] Sagita, R. A., \& Sugiarto, H. "Penerapan Metode Waterfall Pada Sistem Informasi Penjualan Furniture Berbasis Web". Indonesian Journal on Networking and Security, volume 5 nomr 4, hal: 1-7.tahun 2016.

[10] Sovia, R., \& Febio, J. "Membangun Aplikasi E-Library Menggunakan Html, Php Script, Dan Mysql Database". Jurnal Processor, volume 6 nomor 2. Tahun 2017.

[11] Yogaswara, E., \& Prihartanto, C. "Perancangan Sistem Informasi Penyewaan Bus Pariwisata". Jurnal Lentera ICT, volume 1 nomor 1, hal:34-43. Tahun 2019. 